\title{
Inducing All Our 'Low-Risk' Transplant Candidates: Shall We Or Shall We Not?
}

Keywords: Induction; Rejection; Thymoglobulin; Basiliximab; Low immunological risk

\begin{abstract}
Acute rejection episode (ARE) in an allograft recipient has a negative impact on graft survival, and therefore, preventing ARE is of paramount importance. Induction by antibody preparations is one such strategy that has been proven effective in preventing AREs, but there are certain ambiguities in their use particularly in low immunological risk transplants. Anti-interleukin-2 receptor therapy had gained widespread usage in this group of patients because it does not incur additional risks of infectious and malignant sequelae associated with thymoglobulin. However, recent literature found it to be no better than "no induction" strategy. Thymoglobulin, being frequently used in North America for induction even in low risk group, has been used in variable doses across transplant centers. The minimal possible dose of Thymoglobulin that avoids majority of adverse effects while retaining an optimal treatment benefit has not been clearly defined. Moreover, the effects of induction by antibody preparations on long term graft function and survival remain variable. Majority of the published work on induction immunosuppression is retrospective and is difficult to interpret because of a wide spectrum of maintenance immunosuppressive regimen in vogue. This review of literature has been performed to analyse published literature to assess the efficacy and appropriateness of induction agents in "low risk" transplants. We suggest that "low-risk patients receiving triple-drug immunosuppression (calcineurin inhibitors, an anti-proliferative agent and steroids) do not need 'routine' induction by antibody preparations.
\end{abstract}

\section{Abbreviations}

ARE: Acute Rejection Episodes; ATG: Anti-Thymocyte Globulin; SRTR: Scientific Registry of Transplant Recipients; OPTN: Organ Procurement and Transplantation Network; DGF: Delayed Graft Function; ILBS: Institute of Liver and Biliary Sciences; CMV: Cytomegalovirus; BSX: Basiliximab; IL-2RA: IL-2 Receptor Antagonists; Csa: Cyclosporine; MPA: Mycophenolic Acid; MMF: Mycophenolate Mofetil

\section{Introduction}

Renal transplant is undoubtedly the most physiological treatment option for patients with end-stage renal disease. However, the success of transplant is not without cost in terms of morbidity such as infections, metabolic derangements and malignancies. It is desirable to strike a fine balance between the maximal benefits and least side effects of immunosuppressive drugs. The rationalized use of these drugs is based on immunological risks that is essential to stratify for each patient to prevent post-transplant infective complications, which may be a state of over-immunosuppression on one hand manifesting with repeated and possibly life threatening opportunistic infections, and under-immunosuppression on the other hand presenting as graft-threatening acute rejection episodes (ARE). Immunosuppressive agents used in transplantation are classified as

\section{Journal of}

Urology \& Nephrology

\author{
Vikas Jain ${ }^{1}$, Ajay Sharma ${ }^{2}$ and Ahmed Halawa ${ }^{3^{*}}$ \\ ${ }^{I}$ Department of Renal Transplant and Urology, Institute of Liver and \\ Biliary Sciences, New Delhi, India \\ ${ }^{2}$ Royal Liverpool University Hospital, Director of Core Surgical \\ Training Merseyside, North West of England, Associate Director of \\ Post Graduate Courses in Transplantation, University of Liverpool, \\ UK \\ ${ }^{3}$ Sheffield Teaching Hospitals, University of Sheffield - University of \\ Liverpool, UK \\ Address for Correspondence \\ Ahmed Halawa, Sheffield Teaching Hospitals, University of Sheffield - \\ University of Liverpool, UK, E-mail: ahmed.halawa@sth.nhs.uk \\ Submission: 08 December, 2016 \\ Accepted: 19 January, 2017 \\ Published: 27 January, 2017 \\ Copyright: $\odot 2017$ Jain V, et al. This is an open access article distributed \\ under the Creative Commons Attribution License, which permits \\ unrestricted use, distribution, and reproduction in any medium, provided \\ the original work is properly cited.
}

induction, maintenance or anti-rejection rescue therapies. Induction agents are intense agents that are used to suppress immune system prophylactically at the time of transplantation. These are highly potent agents, not surprisingly, cannot be used in long term. Agents used for maintenance therapy are less potent than induction agents. In simple terms, side effects of immunosuppression are directly proportional to potency. Rescue therapy is more or less similar to induction when it comes to potency and side effects except that it is used to treat a proven or suspected ARE.

Induction agents are used in the immediate peri-operative period to ensure maximum immune suppression immediately post-transplant when the risk of acute 'allograft-decimating' immunological events is at its highest. It is not mandatory to use induction in all the situations, however. They form an integral part of immune-suppression protocols in certain clinical situations like [1]:

1. In sensitized individuals (patients with prior history of transplant, transfusions, or multiple pregnancies),

2. Patients in whom late introduction of calcineurin inhibitors (CNI) is desirable such as extended criteria donor organs,

3. As a part of steroid-minimization or withdrawal regimens, and

4. In "high risk individuals" based on risk stratification.

The process of stratifying of immunological risk of a patient into low, intermediate or high risk category (Table 1) is based on histocompatibility testing, antibody screening and donor lymphocyte crossmatch in order to enable rationalization of induction therapy.

On one end of the spectrum are "high-risk candidates", in whom the role of induction therapy cannot be underscored enough in 


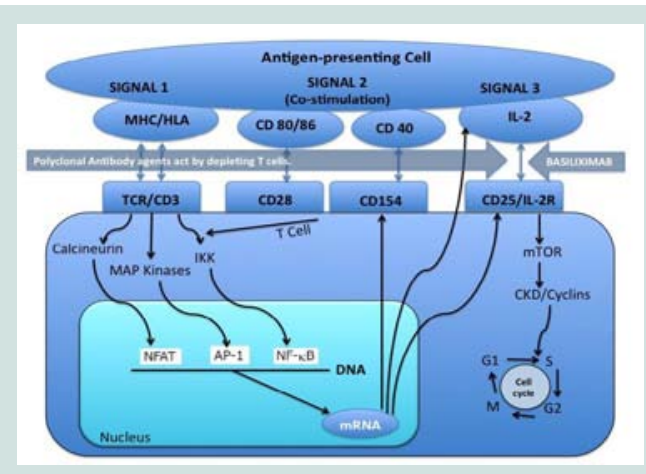

Figure 1: 3-signal model of T-cell activation and mechanism of action of commonly used induction agents.

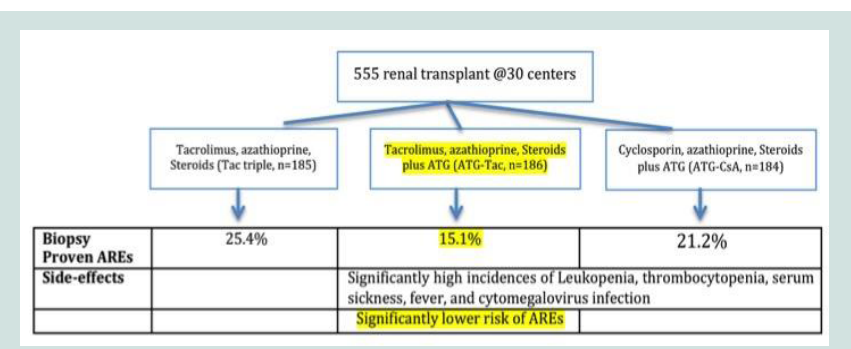

Figure 2: Biopsy-proven ARE.

preventing ARE and, thereby, improving short and long allograft outcome. These agents play a vital role in preventing both clinical and "subclinical" AREs in high-risk individual [2]. Subclinical AREs have been the prime focus of interest in high-risk individuals in recent times, as it could be an important risk factor for chronic allograft nephropathy and graft loss in these patients [3]. On the other end of spectrum, the use of induction can be termed as overkill in the "low risk candidates". As per SRTR/OPTN 2010 annual data report, close to $83 \%$ of renal transplants done in United States use antibody preparations for induction [4].

In this article, the authors discuss various induction agents and primarily focusing on their role in "low" risk transplant candidates.

\section{Classification of induction agents}

Induction agents broadly fall into one of the following three categories:

1. Polyclonal antibody preparations

2. Monoclonal antibodies (MAbs), and

3. Fusion proteins (engineered glycoprotein receptor-antibody hybrids).

The induction agents in current use are biological agents, collectively they are also known as 'biologics'. Another way of classifying them is into 'depleting' antibodies and 'non-depleting' antibodies (Table 2).

Depleting agents act by depleting the target cells ( $\mathrm{T}$ cells/B cells or both). These agents were primarily described for use in rescue conditions like steroid-resistant acute cellular rejections or severe vascular rejections. However, currently they are being increasingly utilized for induction especially in "high" risk recipients.

Non-depleting agents are the primary agents used for induction, they are of no use as rescue agents.

Figure 1 describes the 3-signal model of T-cell activation and mechanism of action of commonly used induction agents.

\section{Polyclonal Antibody Preparations}

As the name suggests, these preparations act on multiple targets, both lymphocyte and non-lymphocyte cell types. Though, their main function is lymphocyte depletion but their cross reactivity with other hematopoietic cell types results in side-effects like anemia, thrombocytopenia and neutropenia. These side effects frequently become reasons for their dose limitations and, at times, discontinuation also. The available agents in this category are:
a. Anti-lymphocyte serum
b. Anti-lymphocyte globulin
c. Anti-thymocyte globulin (ATG)
a. Rabbit-origin
b. Equine (horse)-origin

\section{Role of polyclonal antibodies in pre-cyclosporine era}

In 1960s and 70s, steroids and azathioprine were the mainstay of immunosuppressive therapy in renal transplantation. This regimen was associated with unacceptably high ARE acute and graft loss. Polyclonal antibody preparations used to be given for 2-3 weeks in the immediate post-transplant period, to reinforce the effect of steroids and azathioprine. The end result was a delay in the onset of acute rejection but the strategy did not improve long-term survival [5-7].

\section{Role of polyclonal antibodies in cyclosporine era}

Cyclosporine was introduced for use in renal transplant in 1978 that led to a decline in the use of polyclonal preparations for

Table 1: The process of stratifying of immunological risk of a patient into low, intermediate or high risk category.

\begin{tabular}{|l|l|}
\hline $\begin{array}{l}\text { Immunological } \\
\text { Risk }\end{array}$ & Principles of risk stratification \\
\hline Low & The absence of donor directed sensitization of HLA \\
\hline Intermediate & $\begin{array}{l}\text { Absence of historic DSA or presence of low level of DSA at } \\
\text { the time of transplantation }\end{array}$ \\
\hline High & $\begin{array}{l}\text { Presence of high levels of circulating antibodies specific for } \\
\text { mismatched donor HLA present at the time of transplantation }\end{array}$ \\
\hline
\end{tabular}

Table 2: Classification of 'depleting' antibodies and 'non-depleting' antibodies.

\begin{tabular}{|l|l|}
\hline \multirow{2}{*}{ Depleting Antibodies } & Polyclonal antibody: Horse or Rabbit ATG \\
\hline & $\begin{array}{l}\text { Mouse Monoclonal anti-CD3 antibody (Muromonab } \\
\text { D3) }\end{array}$ \\
\hline & $\begin{array}{l}\text { Humanized Monoclonal anti-CD52 antibody } \\
\text { (Alemtuzumab) }\end{array}$ \\
\hline $\begin{array}{l}\text { Chimeric B cell depleting Monoclonal anti-CD20 } \\
\text { antibody (Rituximab) }\end{array}$ \\
\hline $\begin{array}{l}\text { Non-depleting } \\
\text { antibodies }\end{array}$ & $\begin{array}{l}\text { Humanized Monoclonal anti-CD25antibody } \\
\text { (Daclizumab) }\end{array}$ \\
\hline & Chimeric Monoclonal anti-CD25antibody (Basiliximab) \\
\hline
\end{tabular}


ISSN: $2380-0585$

Table 3: Different dosing regimens depending on the profile of patients.

\begin{tabular}{|c|c|c|c|}
\hline Authors & Dose used & No. of patients & Conclusion \\
\hline Agha et al. [18] & $\begin{array}{l}3 \mathrm{mg} / \mathrm{kg} \text { intra-operatively and } 1.5 \\
\mathrm{mg} / \mathrm{kg} \text { daily for } 2 \text { days }\end{array}$ & 40 & $\begin{array}{l}\text { Thymoglobulin administered for } 3 \text { days affords comparable } \\
\text { benefit to a } 7 \text {-day course }(1.5 \mathrm{mg} / \mathrm{kg} \text { for } 7 \text { days, beginning intra- } \\
\text { operatively) }\end{array}$ \\
\hline Gurck-Turner et al. [19] & $\begin{array}{l}\text { Group1: } 7.5 \mathrm{mg} / \mathrm{kg} \text { LBW } \\
\text { Group2: Higher doses }\end{array}$ & $\begin{array}{l}\text { Group 1: } 33 \\
\text { Group 2: } 63\end{array}$ & $\begin{array}{l}\text { They recommend not to use }>5 \text { doses }(1.5 \mathrm{mg} / \mathrm{kg}) \text { for induction in } \\
\text { high-risk group. }\end{array}$ \\
\hline Hardinger et al. [20] & $\begin{array}{l}\text { Group1: } 1.5 \mathrm{mg} / \mathrm{kg} \times 4 \text { days } \\
\text { Group2: } 2 \mathrm{mg} / \mathrm{kg} \times 3 \text { days }\end{array}$ & 59 patients in each group & $\begin{array}{l}\text { Shorter, more intense dosing of rATG is safe and effective. The } \\
\text { 3-day dose strategy resulted in a clinically shorter length of stay and } \\
\text { may result in cost savings. }\end{array}$ \\
\hline Laftavi et al. [21] & $3-5 \mathrm{mg} / \mathrm{kg}$ total dose & $\begin{array}{l}\text { Deceased donor: } 124 \\
\text { Living donor: } 64\end{array}$ & $\begin{array}{l}\text { Low-dose } \mathrm{rATG}(3-5 \mathrm{mg} / \mathrm{kg} \text { total dose }) \text { is safe and efficacious in } \\
\text { low-risk kidney transplant recipients. }\end{array}$ \\
\hline Wong et al. [22] & $\begin{array}{l}\text { Group A: } 1 \mathrm{mg} / \mathrm{kg} \times 3 \text { days } \\
\text { Group B: } 1.5 \mathrm{mg} / \mathrm{kg} \times 3 \text { days }\end{array}$ & $\begin{array}{l}\text { Group A: } 7 \\
\text { Group B: } 9\end{array}$ & $\begin{array}{l}\text { Short course (3-day) induction therapy with either } 1.0 \text { or } 1.5 \mathrm{mg} / \mathrm{kg} / \\
\text { day of rATG appears to be practical, safe and efficacious. }\end{array}$ \\
\hline Klem et al. [23] & $\begin{array}{l}\text { Group 1: } 1.5 \mathrm{mg} / \mathrm{kg} \times 3 \text { doses } \\
\text { Group 2: } 1.5 \mathrm{mg} / \mathrm{kg} \times 4 \text { doses }\end{array}$ & $\begin{array}{l}\text { Group 1: } 39 \\
\text { Group 2: } 44\end{array}$ & $\begin{array}{l}\text { 3- or } 4 \text {-dose course of } \mathrm{rATG}(1.5 \mathrm{mg} / \mathrm{kg} / \mathrm{dose}) \text { provides excellent } \\
\text { protection against AREs even in increased risk patients. } \\
\text { 3-day dose is associated with short hospital stay and cost savings. }\end{array}$ \\
\hline Stevens et al. [24] & $\begin{array}{l}\text { Single dose group: } 6 \mathrm{mg} / \mathrm{kg} \\
\text { Multiple dose group: } 1.5 \mathrm{mg} / \mathrm{kg} \times 4 \\
\text { doses }\end{array}$ & $\begin{array}{l}\text { Single dose: } 76 \\
\text { Multiple dose: } 76\end{array}$ & $\begin{array}{l}\text { Single dose rATG induction is at least equal in safety to conventional, } \\
\text { divided dose regimen with improved early graft function. }\end{array}$ \\
\hline
\end{tabular}

induction, for the fear of increased risk of infective and malignant complications $[8,9]$.

\section{Role of polyclonal antibodies in the present era of tacrolimus-} based triple immunosuppression

Tacrolimus received US-FDA approval for use in kidney transplantation in 1997 i.e. three years after its use started in liver transplant. Since than, tacrolimus-based triple immunosuppression regimen (tacrolimus, mycophenolate and steroids) has become standard of care for maintenance immunosuppression. In an estimate, by 2009 , close to $85 \%$ of renal recipients are discharged on tacrolimus [10]. Many trials have focused on the use of polyclonal agents with this intense regimen and found a statistically significant reduction in the AREs, but at the expense of infectious complications and without any significant changes in the long-term outcome $[11,12]$.

In a 6-month, open-label, randomized, prospective French multicentric study [11], 555 patients were randomly assigned to tacrolimus triple therapy (Tac triple, $\mathrm{n}=185$ ), ATG induction with tacrolimus (ATG-Tac, $\mathrm{n}=186$ ), or ATG induction with CsA microemulsion (ATG-CsA, $n=184$ ). All three groups received azathioprine and corticosteroids. The primary endpoint was incidence and time to first biopsy-proven ARE. Figure 2 summarizes the structure and results of this trial.

In another similar multi-centric French study [12], which compared ATG induction with no induction in recipients with tacrolimus-based immunosuppression, it was concluded that ATG induction was associated with significantly lower risk of AREs (15.2\%, as compared to $30.4 \%$ in non-induction group, $\mathrm{p}=0.001$ ), but the therapy increased incidences of infections particularly CMV infection.

Now, the important point of discussion is whether this additional risk of infective morbidity is worth taking or not! The answer is probably "no" in low-risk candidates but in high-risk candidates it is worthwhile. A number of authors have demonstrated the superiority of ATG induction in patients who receive grafts from extended criteria donors or patients who are at high risk of rejection like re- transplants and patients with DGF $[13,14]$.

A favorable effect of ATG was found on early mechanisms of ischemia-reperfusion injury (IRI) in a primate model [15]. It was discovered that ATG, by virtue of its properties of T-cell depletion and causing functional impairment of non-depleted circulating lymphocytes, reduce leukocyte adherence to the antigen-presenting endothelial cells. As a result, the allo-recognition events cannot take place in the post-transplant period of reperfusion and, thereby, immunological onslaught on allograft is blunted.

Another important indication for induction with polyclonal agents, in modern era, is patient in whom CNIs need to be avoided. CNI-free regimen is particularly desired in kidneys obtained from expanded-criteria donors, as these kidneys are relatively more prone to CNI-mediated vasoconstriction in the immediate post-transplant period and nephrotoxicity with chronic use. Furian and colleagues have described a CNI-free protocol for marginal kidneys (dual kidney grafts from elderly donors) [16]. The protocol included induction with ATG, and maintenance therapy with sirolimus, steroids and mycophenolate mofetil. They have reported excellent results with lower incidence of DGF and better renal functions in this group.

\section{Availability in India}

The most commonly available and used agent is anti-thymocyte

Table 4: Percentages of side effects associated with rATG.

\begin{tabular}{|l|c|}
\hline Side-effect & Percentage \\
\hline Fever & $63 \%$ \\
\hline Chills & $57 \%$ \\
\hline Headache & $40 \%$ \\
\hline Nausea & $37 \%$ \\
\hline Diarrhea & $37 \%$ \\
\hline Malaise & $13 \%$ \\
\hline Dizziness & $9 \%$ \\
\hline Pain & $46 \%$ \\
\hline
\end{tabular}


Table 5: Classification of monoclonal antibodies based on the CD nomenclature.

\begin{tabular}{|l|c|c|}
\hline MAbs & Origin & Target protein \\
\hline Muromonab (OKT3) & Murine & Anti-CD3 \\
\hline Daclizumab & Humanized & Anti-CD25 IgG1 \\
\hline Basiliximab & Chimeric mouse-human & Anti-CD25 IgG1 \\
\hline Alemtuzumab & Humanized & Anti-CD52 \\
\hline Rituximab & Chimeric & Anti-CD20 \\
\hline
\end{tabular}

globulin (ATG). In India, rabbit-origin ATG (rATG, GenzymeSanofi) labeled as Thymoglobulin is in use. It is available as $25 \mathrm{mg}$ vial This preparation is extracted and purified from the serum of thymic tissue-immunized rabbits.

\section{Dosing schedule for induction}

Thymoglobulin does not have US-FDA approval for use as induction agent in kidney transplant. Induction therapy remains an off-label indication of rATG. Still, it is the most commonly used induction agent worldwide. According to one estimate, almost $60 \%$ of recipients receive Thymoglobulin induction in US alone [17].

The drug has dose dependent T-cell depletion and side-effect profile. Authors worldwide [18-24], depending on the profile of patients, have used different dosing regimens (Table 3), for e.g. lower doses for low immunological risk and elderly patients. An ideal dose would be one with maximal benefit and least side effects, and is yet to be ascertained.

One clear inference from Table 3 is that there is no agreed upon ATG dose for induction. The authors have their own dosing regimens depending on their experience (i.e. 'impression based medicine'), but one question that should be asked before selecting a particular dose is what is the lowest optimal dose that confers the most balanced therapeutic benefit? Kho et al. have made an attempt to shed some light on this by evaluating the effect of different doses of rATG on T cells, B cells and NK cells [25]. They had following conclusions from their study:

1. The ultra-low total dose of $1.5 \mathrm{mg} / \mathrm{kg}$ of $\mathrm{r}-\mathrm{ATG}$ results in depletion of peripheral $\mathrm{T}$ and NK cells for at least one week.

2. A total dose of $3 \mathrm{mg} / \mathrm{kg}$ rTAG results in significantly lower $\mathrm{T}$ cells for one month, however at one-year the $\mathrm{T}$ cell count recovers to baseline values.

3. The T cell depleting effect of a total dose of $6 \mathrm{mg} / \mathrm{kg}$ of $\mathrm{rATG}$ lasts for almost one year.

4. The effect on B cell remains variable depending on the batch-tobatch variability in the presence of $B$ cell specific antibodies.

The inferences made from their study may be used as guiding principles on the dose of rATG as induction agent depending on the risk involved.

\section{Adverse-effects of ATG}

The most common acute adversities due to ATG are related to either bone marrow suppression or transient cytokine release [26].
The effects due to cytokine release include serum sickness, chills, fever, rash and urticaria. As many as $20 \%$ of patients experience chills and fever, which usually respond to hydrocortisone, paracetamol and anti-histaminics. Table 4 summarizes the percentages of side effects associated with rATG.

Bone marrow suppression in the form of neutropenia, thrombocytopenia or both is seen in as many as $30 \%$ patients receiving ATG. Marrow suppression frequently becomes the reason of ATG dose adjustments or even discontinuation. For example, doses may be halved or administered at less frequent intervals if the platelet count drops to $50,000-75,000$ platelets $/ \mathrm{mm}^{3}$ or the white blood cell count drops to 2,000-3,000 cells $/ \mathrm{mm}^{3}$. Discontinuation of the drug should be considered if these values drop below 50,000 platelets $/ \mathrm{mm}^{3}$ or to $<$ 2,000 white blood cells $/ \mathrm{mm}^{3}$ [27].

Life-threatening anaphylaxis, pulmonary edema, refractory hypotension/hypertension are infrequent. Rash typically occurs late in the treatment, usually towards the end of schedule. It is self-limiting and responds to symptomatic treatment. Primary viral infections caused by cytomegalovirus, herpes simplex, epstein-barr virus and varicella are common associations with ATG use. Other dose-related haematological complications include anemia, thrombocytopenia and neutropenia.

De novo cancers particularly post-transplant lymphoproliferative disorders (PTLD) has been described to occur more frequently with ATG use. The European and American registries differ on this aspect of ATG. The European [28] registry shows an increased occurrence of PTLD with thymoglobulin, though American [29] registry does not show any difference. The probable reason for this difference is different cohorts in two registries: while European registry included cohorts before 2000s treated with higher doses, the American cohorts were after 2000 and received low-dose ATG.

A 2015 update by Hertig and Zuckermann on rATG and risk of PTLD in solid organ transplantation summarizes that it is difficult to interpret the data due to retrospective nature of the studies, however, one message is clear "the lower the dose, the lower the risk" [30].

\section{Monoclonal Antibodies (MAbs)}

Monoclonal antibodies are described based on the targeted cell surface proteins they act upon and these surface proteins are classified

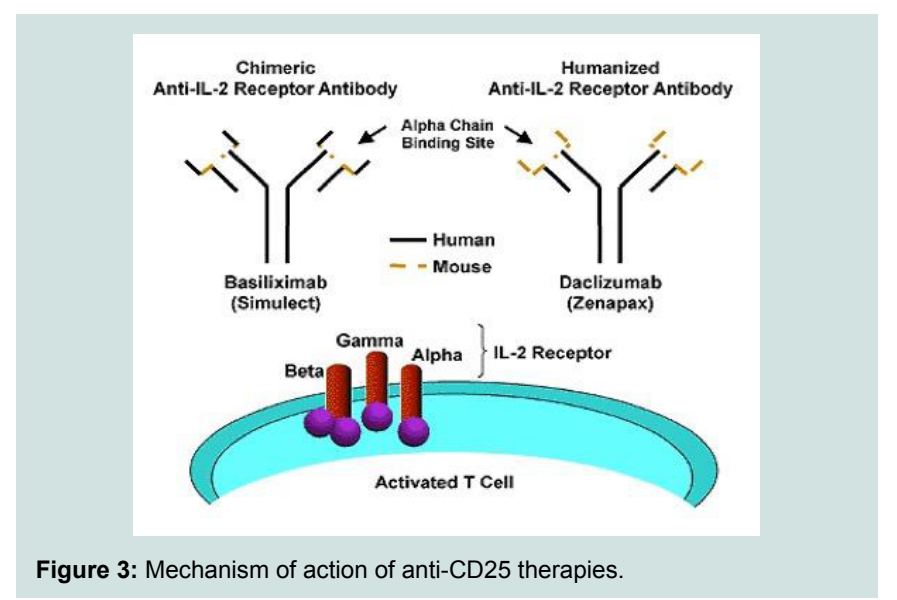


based on the $\mathrm{CD}$ nomenclature.

They can also be classified based on the method for deriving them for e.g. murine, chimeric or humanized (Table 5).

\section{Rituximab}

Rituximab is a chimeric MAb specific for CD20. It is commonly used as a component of induction regimen in transplants across blood group barrier (ABO-incompatible) or across positive cross match, after antibody removal [31-33].

\section{Basiliximab}

CD25 was the first molecule to be targeted successfully with humanized monoclonal antibody. The figure 2 shows the mechanism of action of anti-CD25 therapies. Basiliximab is a chimeric mousehuman anti-CD 25 IgG1.

The main advantages of IL-2 receptor antagonist over ATG are:

1. These agents have highly favorable safety profile [33].

2. Therapy is not associated with cytokine release syndrome or serum sickness.

3. No increase in infectious complications or wound healing issues has been reported in clinical studies.

4. PTLD risk is more or less similar to no induction agent used [34].

5. These agents have fixed dose, body-weight independent schedule so ease of administration.

The disadvantages over rATG are as follows:

1. These agents have only a modest efficacy and cannot be used as rescue agents.

2. IL-2 receptor blocker induction is not that strong that it would allow CNI mono-therapy or CNI withdrawal/avoidance [35].

\section{Dosing schedule}

It is available as $20 \mathrm{mg}$ vial and two doses are given. The first dose is given intra-operatively, and a repeat dose is given on day 4 of surgery. The $20 \mathrm{mg}$ vial is diluted in $100 \mathrm{ml}$ normal saline and infused slowly over 20-30 minutes, preferably through a central vein though not mandatory. Pre-medication and test dose are not required (cf. rATG) prior to infusion.

\section{Basiliximab vs. ATG}

Earlier data comparing basiliximab and ATG induction came from Sollinger and colleagues [36]. At the end of 1-year open labeled randomized study, authors concluded that basiliximab combined with early initiation of cyclosporine therapy $(n=70)$ resulted in low ARE rates that were similar to those achieved with ATG combined with delayed cyclosporine $(n=65)$. They advocated basiliximab to be an attractive alternative for induction, to prevent AREs in renal transplant recipients. Its safety profile and weight independent dosing schedule is particularly advantageous. While earlier data was encouraging, recent data [21] show conflicting results particularly in low-risk candidates.

\section{Daclizumab}

Daclizumab is humanized anti-CD25 IgG1. It was commercially available for use till 2009, after that it was withdrawn from market.

\section{Alemtuzumab}

Alemtuzumab, commonly known as Campath, is a humanized anti-CD52 IgG1. CD52 is present on virtually all B cells and T cells, as well as macrophages, NK cells, and some granulocytes. When the alemtuzumab antibody binds to CD52, it triggers an antibodydependent lysis of these cells. The depletion of lymphocytes is so marked that it takes several months or even up to one year after administration for a patient's immune system to be fully reconstituted. It is marketed for use in the treatment of B-cell chronic lymphocytic leukemia, but has been widely used off-label as an induction agent in renal transplantation $[37,38]$. The usual dose is 30 mg subcutaneously to be given intra-operatively before reperfusion and another on day 1 postoperatively. The adverse reactions are mainly due to its depletional effects on all the 3 cell lines, resulting in neutropenia (70\%), thrombocytopenia (52\%) and anemia (47\%). Others include nausea, vomiting, diarrhea, headache and dizziness. The clinical efficacy and safety of its use has been evaluated in randomized controlled trials. Analphylactoid reaction is potentially lethal (one such instance in Liverpool) if Campath is given interavenously. In patients who are older than 60 years, only one dose is given (Liverpool protocol). Ciancio et al. randomized 90 patients into rATG, alemtuzumab and daclizumab groups, with 30 patients in each one [39]. At the end of one year, there was no difference in the rates of biopsy proven AREs, patient and graft survival and infectious complications. Small number of subjects in each group is possibly the reason why there was no statistical difference in 2 groups.

\section{Fusion Proteins (Engineered Glycoprotein Receptor- Antibody Hybrids)}

\section{Belatacept}

It is a fusion protein composed of the $\mathrm{Fc}$ fragment of human IgG1 linked to the extracellular domain of cytotoxic T-lymphocyteassociated antigen 4 (CTLA-4). The drug selectively inhibits T-cell activation through costimulation blockade. Belatacept was approved by the USFDA in 2011, on the basis, in part, of 3-year data from two phase 3 studies: Belatacept Evaluation of Nephroprotection and Efficacy as First-line Immunosuppression Trial (BENEFIT) and BENEFIT-Extended Criteria Donors (BENEFIT-EXT). A lessintensive belatacept regimen is approved for use only in patients who are positive for Epstein-Barr virus (EBV), given the increased risk of post-transplantation lymphoproliferative disorder, predominantly involving the central nervous system, in EBV-seronegative patients. Patients in the belatacept trial were not prospectively stratified according to EBV status when the study started, since no safety signal was identified on the basis of EBV-negative serostatus. The decision to restrict belatacept for use only in EBV-positive patients was based on the findings of the phase 3 trials.

A recently published report [40] summarizes the final efficacy and safety results up to 7 years (84 months) after transplantation in the intention-to-treat population of BENEFIT. The study had three arms: a more-intensive belatacept arm, a less-intensive belatacept arm and 
cyclosporine arm. The study reported a $43 \%$ reduction in the risk of death or graft loss for both the more-intensive and the less-intensive belatacept regimens as compared with the cyclosporine regimen. Both the belatacept arms had significantly higher mean estimated glomerular filtration rate (eGFR) than cyclosporine group 7 years after transplantation.

\section{Role of induction strategies in low-risk candidates}

A transplant clinician has three possible induction strategies in low-risk recipients:

\section{a. No Induction \\ b. Induction with rATG \\ c. Basiliximab induction}

Kidney Disease Improving Global Outcomes (KDIGO) proposed guidelines for induction in kidney transplant patients in 2009. The recommendations were largely based on randomized controlled trials that compared IL-2RA with ATG and no induction. They recommended that induction with biological agent should be a routine part of the initial immunosuppressive regimen (grade1B) and IL-2RA is the agent of choice (grade 1B), with ATG kept reserved for high immunological risk patients (grade 2B). These trials were later summarized by Cochrane Collaborative group in 2010 [41]. A detailed analysis of this database reveals that the maintenance immunosuppression regimens used by these authors have been supplanted, at present, by tacrolimus and mycophenolic acid based triple regimens. Cyclosporine and azathioprine have largely been superseded by tacrolimus and MPA respectively because of reports of lower rejection rates with later combination [42-44]. With this tacrolimus based triple regimen, the current ARE episodes have already declined to $10-15 \%$, from approximately 40 $50 \%$ in cyclosporine based regimens used in 1990s [42,44,45]. How much further reduction in AREs is expected by "inducing" all low risk candidates is the question one should ask before deciding the immunosuppression protocol.

\section{rATG vs. no induction}

Two randomized trials $[11,12]$ which particularly looked at this, clearly demonstrated the superiority of rATG induction therapy in lowering the incidence of early AREs and delaying the introduction of CNIs. This, however, was associated with significantly high risk of reversible bicytopenia (low platelets and leucocytes) and CMV infection. Despite significantly lowering the incidence of AREs, there seemed to be no significant impact on one-year patient or graft survival.

Another subset of "low-risk" patients in whom rATG can be beneficial are ones in whom early-steroid withdrawal is desirable. This is to reduce the morbidity associated with chronic steroid use; diabetes, weight gain to name a few. A number of authors have shown that induction with rATG allows early (in the first three months) and safe steroid withdrawals [46-50]. A lower or similar AREs was evident in all trials in rATG treated patients, but with better metabolic profile.

\section{Basiliximab vs. no induction}

Gavela et al. retrospectively analyzed 55 low-risk recipients, who either received basiliximab induction $(n=21)$ or no induction $(n=33)$, in the setting of tacrolimus-based maintenance immunosuppression [50]. They did not find any benefit of basiliximab in the study cohort and their observations made them conclude that routine administration of basiliximab cannot be justified in young low immunological risk transplant candidates undergoing tacrolimusbased immunosuppression. Hellemans and colleagues recently questioned the role of induction in standard-risk candidates receiving triple immunosuppression, as the studies [51,52-55] have suggested that absolute risk reduction for AREs conferred by addition of these agents is mere $1-4 \%$, that too without any graft and patient survival advantage. Three of these authors [52-54] retrospectively analyzed U.S. registry data, while Lim et al. analyzed the Australia and New Zealand Dialysis and Transplant registry (ANZDATA) [55]. These authors opined basiliximab induction to be unnecessary in standardrisk population receiving triple immunosuppression. However, basiliximab induction is inferior to Thymoglobulin in the high-risk settings: high number of HLA mismatches, younger recipient age, older donor age, black ethnicity (in the United states), panel reactive antibodies $>0 \%$, presence of donor-specific antibody, delayed onset of graft function and cold ischemia time $>24$ hours [55].

Recently published work of Tanriover et al. which studied the patients from OPTN registry, who received living donor transplant from 2000 to 2012 and maintained on tacrolimus and mycophenolate at discharge [52]. It compared the effectiveness of IL-2RA to other induction agents in 36,153 patients. The study concluded that compared with no-induction therapy, IL2-RA induction was not associated with better outcomes when tacrolimus based triple drug immunosuppression was used in living renal transplant recipients. rATG appears to be an acceptable and possibly the preferred induction alternative for IL2-RA in steroid-avoidance protocols. The major strengths of the study are:

a. Large study population $(\mathrm{n}=36153)$,

b. Standardization of baseline immunosuppression, study period (2000-2012), which is the modern era of maintenance immunosuppression, and

c. The use of propensity score methodology to address the selection bias that is almost certainly present as transplant programs determine the appropriateness of induction therapy for their programs or an individual patient. This statistical approach has not been previously used when addressing this topic and is superior to previous metaanalyses and retrospective analyses that have attempted to compare induction agents.

\section{rATG induction vs. basiliximab induction}

Laftavi et al.published 8-year follow-up of their low risk cohorts induced either by low dose ATG (3-5 $\mathrm{mg} / \mathrm{kg}$ total) or basiliximab [21]. They classified their retrospective cohorts into four groups:

Group 1: Deceased donor transplant recipients induced with basiliximab $(n=40)$

Group 2: Deceased donor transplant recipients induced with lowdose $\operatorname{rATG}(\mathrm{n}=124)$ 
Group 3: Living donor transplant recipients induced with basiliximab $(n=20)$

Group 4: Living donor transplant recipients induced with lowdose $\operatorname{rATG}(\mathrm{n}=64)$

They concluded that low-dose ATG therapy was associated with lower rejection rate in living donor transplant recipients compared to basiliximab. In deceased renal transplant recipients of low-dose rATG, long-term graft survival rate was superior when compared to basiliximab. Compared to basiliximab induction therapy, low-dose rATG did not increase the average hospital stay, malignancy rate or the incidence of viral or bacterial infections.

Using Thymoglobulin, the relative risk of AREs is almost $50 \%$ lower than with basiliximab in high-risk patients [52,53]. With this extent of risk reduction, Thymoglobulin scores over basiliximab as induction agent in high-risk candidates, but cannot be justified in low-risk candidates.

Tanriover and colleagues recently published the analysis of patients from OPTN registry, who received deceased donor transplant [56]. The conclusions drawn from the study were similar to their published work on living donor transplants from same registry [47]. They concluded that $\mathrm{r}-\mathrm{ATG}$ confers better graft survival over basiliximab particularly in steroid avoidance protocols.

In an open randomized multi-centric French study, the safety and efficacy of basiliximab induction was compared with ATG induction with delayed introduction of CNI (cyclosporine in this study) in low immunological risk transplant candidates receiving MMF and steroids from day0. This study was unique as all the other treatment parameters were equivalent in both the ATG and basiliximab groups [57]. Authors have reported comparable biopsy-proven AREs in both the groups (ATG 9.4\% and basiliximab 9.6\%) at one year.

Another prospective randomized study compared induction with IL-2RA versus ATG in low risk transplants [58]. The authors reported similar patient and graft survival at 5 years. They concluded that the induction therapy has no major impact on long-term outcome of low risk transplants.

\section{What Induction in 2017?}

This is a difficult question to answer because there is still no clear verdict, and reaching a logical conclusion seems a distant possibility because there has never been a randomized controlled double blind clinical trial comparing induction agents only in low risk patients using triple drug tacrolimus based immunosuppression. Majority of the published work is retrospective in nature and includes a variety of maintenance immunosuppression.

Given the low incidence of ARE (approaching 10\%) in low-risk candidates, it may be not be possible to have randomized controlled double-blind clinical trials comparing basiliximab with no induction or rATG because the sample size required of these studies to show a statistically and clinically meaningful difference is too big and, therefore, too expensive. From the sponsor's point of view, investment in to such a study is too risky from 'business point of view' given the current widespread use of induction agents anyway.
At present, a phase IV open label randomized multicentre prospective study [59] to compare ATG in parallel with a control group treated by basiliximab is under way. The study was initiated at the Nantes University hospital in July 2014. The data will be collected till April 2018, and results are likely to be published by 2019. The aim is to determine whether a short course of ATG can decrease the incidence of DGF in comparison with basiliximab in kidney transplant recipients with low immunological risk but high DGF risk. The main expected benefits of this study are:

(i) The reduction of unjustified ATG over-prescriptions associated with serious adverse events,

(ii) The reduction of chance losses related to ATG underprescription,

(iii) The decrease in the incidence of DGF, and

(iv) The reduction in hospitalization duration and number of post transplantation dialysis sessions.

Until this ongoing trial throws some light on the rationalization of induction agents in low-risk candidates, each center should have its own induction protocol based on published literature which should take into account the cost-implications and risk-benefit ratio.

\section{Conclusions}

Low-risk patients, receiving triple immunosuppression (CNI, anti-proliferative agent and steroids) do not need 'routine' induction by antibody preparations. The patients in whom late initiation of CNI or early withdrawal of steroids is required such as those transplanted with kidney from extended criteria organ donors, either Campath or rATG induction is safe and efficacious. Basiliximab induction has no proven advantage over "no induction" strategy in low immunological risk candidates. It just adds to the cost and, therefore, its routine use is not justified in this scenario.

\section{References}

1. Cornell LD, Smith RN, Colvin RB (2008) Kidney transplantation: mechanisms of rejection and acceptance. Annu Rev Pathol 3: 189-220.

2. Nashan B (2005) Antibody induction therapy in renal transplant patients receiving calcineurin-inhibitor immunosuppressive regimens: a comparative review. BioDrugs 19: 39-46.

3. Humar A, Hassoun A, Kandaswamy R, Payne WD, Sutherland DE, et al. (1999) Immunologic factors: the major risk for decreased long-term renal allograft survival. Transplantation 68: 1842-1846.

4. (2012) Organ procurement and transplantation network and scientific registry of transplant recipients 2010 data report. Am J Transplant 12 Suppl 1: 1-156.

5. Cosimi AB, Wortis HH, Delmonico FL, Russell PS (1976) Randomized clinical trial of antithymocyte globulin in cadaver renal allograft recipients: importance of T cell monitoring. Surgery 80: 155-163.

6. Howard RJ, Condie RM, Sutherland DE, Simmons RL, Najarian JS (1981) The use of antilymphoblast globulin in the treatment of renal allograft rejection. Transplant Proc 13(1 Pt 1): 473-474.

7. Wechter WJ, Morrell RM, Bergan J, Rosenberg JC, Turcotte J, et al. (1979) Extended treatment with antilymphocyte globulin (ATGAM) in renal allograft recipients. Transplantation 28: 365-367.

8. Merion RM, White DJ, Thiru S, Evans DB, Calne RY (1984) Cyclosporine: five years experience in cadaveric renal transplantation. N Engl J Med 310: 148-154. 
9. Oyer PE, Stinson EB, Jamieson SW, Hunt SA, Billingham M, et al. (1983) Cyclosporin-A in cardiac allografting: a preliminary experience. Transplant Proc 15: 1247-1252.

10. Shapiro R, Young JB, Milford EL, Trotter JF, Bustami RT, et al. (2005) Immunosuppression: evolution in practice and trends, 1993-2003. Am J Transplant 5: 874-886.

11. Charpentier B, Rostaing L, Berthoux F, Lang P, Civati G, et al. (2003) A three-arm study comparing immediate tacrolimus therapy with antithymocyte globulin induction therapy followed by tacrolimus or cyclosporine $A$ in adult renal transplant recipients. Transplantation 75: 844-851.

12. Mourad G, Garrigue V, Squifflet JP, Besse T, Berthoux F, et al. (2001) Induction versus noninduction in renal transplant recipients with tacrolimusbased immunosuppression. Transplantation 72: 1050-1055.

13. Cecka JM, Gjertson D, Terasaki PI (1993) Do prophylactic antilymphocyte globulins (ALG and OKT3) improve renal transplant survival in recipient and donor high-risk groups? Transplant Proc 25(1 Pt 1): 548-549.

14. Shield CF, Edwards EB, Davies DB, Daily OP (1997) Antilymphocyte induction therapy in cadaver renal transplantation: a retrospective, multicenter United Network for Organ Sharing Study. Transplantation 63: 1257-1263.

15. Chappell D, Beiras-Fernandez A, Hammer C, Thein E (2006) In vivo visualization of the effect of polyclonal antithymocyte globulins on the microcirculation after ischemia/reperfusion in a primate model. Transplantation 81: 552-558.

16. Furian L, Baldan N, Margani G, Ekser B, Silvestre C, et al. (2007) Calcineurin inhibitor-free immunosuppression in dual kidney transplantation from elderly donors. Clin Transplant 21: 57-62.

17. Wiseman AC (2015) Induction therapy in renal transplantation: Why? What agent? What dose? We may never know. Clin J Am Soc Nephrol 10: 923-925.

18. Agha IA, Rueda J, Alvarez A, Singer GG, Miller BW, et al. (2002) Short course induction immunosuppression with thymoglobulin for renal transplant recipients. Transplantation 73: 473-475.

19. Gurk-Turner C, Airee R, Philosophe B, Kukuruga D, Drachenberg C, et al (2008) Thymoglobulin dose optimization for induction therapy in high risk kidney transplant recipients. Transplantation 85: 1425-1430.

20. Hardinger KL, Rasu RS, Skelton R, Miller BW, Brennan DC (2010) Thymoglobulin induction dosing strategies in a low-risk kidney transplant population: three or four days? J Transplant 2010: 957549.

21. Laftavi MR, Alnimri M, Weber-Shrikant E, Kholi R, Said M, et al. (2011) Lowdose rabbit antithymocyte globulin versus basiliximab induction therapy in low-risk renal transplant recipients: 8-year follow-up. Transplant Proc 43: 458-461.

22. Wong W, Agrawal N, Pascual M, Anderson DC, Hirsch HH, et al. (2006) Comparison of two dosages of thymoglobulin used as a short-course for induction in kidney transplantation. Transpl Int 19: 629-635.

23. Klem P, Cooper JE, Weiss AS, Gralla J, Owen P, et al. (2009) Reduced dose rabbit anti-thymocyte globulin induction for prevention of acute rejection in high-risk kidney transplant recipients. Transplantation 88: 891-896.

24. Stevens RB, Mercer DF, Grant WJ, Freifeld AG, Lane JT, et al. (2008) Randomized trial of single-dose versus divided-dose rabbit anti-thymocyte globulin induction in renal transplantation: an interim report. Transplantation 85: 1391-1399

25. Kho MM, Bouvy AP, Cadogan M, Kraaijeveld R, Baan CC, et al. (2012) The effect of low and ultra-low dosages thymoglobulin on peripheral T, B and NK cells in kidney transplant recipients. Transpl Immunol 26: 186-190.

26. Debets JMH, Leunissen KML, van Hooff HJ, van der Linden CJ, Buurman WA (1989) Evidence of involvement of tumor necrosis factor in adverse reactions during treatment of kidney allograft rejection with antithymocyte globulin. Transplantation 47: 487-492.

27. Hardinger KL (2006) Rabbit antithymocyte globulin induction therapy in adult renal transplantation. Pharmacotherapy 26: 1771-1783.

28. Opelz G, Naujokat C, Daniel V, Terness P, Döhler B (2006) Disassociation between risk of graft loss and risk of non-hodgkin lymphoma with induction agents in renal transplant recipients. Transplantation 81: 1227-1233.

29. Caillard S, Dharnidharka V, Agodoa L, Bohen E, Abbott K (2005) Posttransplant lymphoproliferative disorders after renal transplantation in the United States in era of modern immunosuppression. Transplantation 80: 1233-1243.

30. Hertig A, Zuckermann A (2015) Rabbit antithymocyte globulin induction and risk of post-transplant lymphoproliferative disease in adult and pediatric solid organ transplantation: An update. Transpl Immunol 32: 179-187.

31. Vo AA, Peng A, Toyoda M, Kahwaji J, Cao K, et al. (2010) Use of intravenous immune globulin and rituximab for desensitization of highly HLA-sensitized patients awaiting kidney transplantation. Transplantation 89: 1095-1102.

32. Fuchinoue S, Ishii Y, Sawada T, Murakami T, Iwadoh K, et al. (2011) The 5 -year outcome of $\mathrm{ABO}$-incompatible kidney transplantation with rituximab induction. Transplantation 91: 853-857.

33. Rehman S, Meier-Kriesche HU, Scornik J (2010) Use of intravenous immune globulin and rituximab for desensitization of highly human leukocyte antigensensitized patients awaiting kidney transplantation. Transplantation 90: 932.

34. Cherikh WS, Kauffman HM, McBride MA, Maghirang J, Swinnen LJ, et al. (2003) Association of the type of induction immunosuppression with posttransplant lymphoproliferative disorder, graft survival, and patient survival after primary kidney transplantation. Transplantation 76: 1289-1293.

35. Parrott NR, Hammad AQ, Watson CJ, Lodge JP, Andrews CD (2005) Multicenter, randomized study of the effectiveness of basiliximab in avoiding addition of steroids to cyclosporine a monotherapy in renal transplant recipients. Transplantation 79: 344-348.

36. Sollinger H, Kaplan B, Pescovitz MD, Philosophe B, Roza, et al. (2001) Basiliximab versus antithymocyte globulin for prevention of acute renal allograft rejection. Transplantation 72: 1915-1919.

37. Morris PJ, Russell NK (2006) Alemtuzumab (Campath-1H): a systematic review in organ transplantation. Transplantation 81: 1361-1367.

38. Ciancio G, Burke GW (2008) Alemtuzumab (Campath-1H) in kidney transplantation. Am J Transplant 8: 15-20.

39. Ciancio G, Burke GW, Gaynor JJ, Carreno MR, Cirocco RE, et al. (2005) A randomized trial of three renal transplant induction antibodies: early comparison of tacrolimus, mycophenolate mofetil, and steroid dosing, and newer immune-monitoring. Transplantation 80: 457-465.

40. Vincenti F, Rostaing L, Grinyo J, Rice K, Steinberg S, et al. (2016) Belatacept and long-term outcomes in kidney transplantation. N Engl J Med 374: 333343.

41. Webster AC, Ruster LP, McGee R, Matheson SL, Higgins GY, et al. (2010) Interleukin 2 receptor antagonists for kidney transplant recipients. Cochrane Database Syst Rev: CD003897.

42. (2014) OPTN/SRTR: Annual report 2012.

43. Webster A, Woodroffe RC, Taylor RS, Chapman JR, Craig JC (2005) Tacrolimus versus cyclosporin as primary immunosuppression for kidney transplant recipients. Cochrane Database Syst Rev. CD003961.

44. Ekberg H, Tedesco-Silva H, Demirbas A, Vítko S, Nashan B, et al. (2007) Reduced exposure to calcineurin inhibitors in renal transplantation. $N$ Engl J Med 357: 2562-2575.

45. Meier-Kriesche HU, Schold JD, Srinivas TR, Kaplan B (2004) Lack of improvement in renal allograft survival despite a marked decrease in acute rejection rates over the most recent era. Am J Transplant 4: 378-383.

46. Martin ST, Roberts KL, Malek SK, Tullius SG, Va divel N, et al. (2011) Induction treatment with rabbit antithymocyte globulin versus basiliximab in renal transplant recipients with planned early steroid withdrawal. Pharmacotherapy 31: 566-573.

47. Laftavi MR, Stephan R, Stefanick B, Kohli R, Dagher F, et al. (2005) Randomized prospective trial of early steroid withdrawal compared with lowdose steroids in renal transplant recipients using serial protocol biopsies to assess efficacy and safety. Surgery 137: 364-371. 
48. Woodle ES, Alloway R, Rike A, Roy-Chaudhury P, Tevar A, et al. (2007) Corticosteroid elimination: the Cincinnati experience. Clin Transpl 2007: 5160.

49. Lebranchu Y, Aubert P, Bayle F, Bedrossian J, Berthoux F, et al. (2000) Could steroids be withdrawn in renal transplant patients sequentially treated with ATG, cyclosporine, and cellcept? One-year results of a double-blind, randomized, multicenter study comparing normal dose versus low-dose and withdrawal of steroids. M 55002 French Study Group. Transplant Proc 32: 396-397.

50. Gavela Martínez E, Avila Bernabeu Al, Sancho Calabuig A, Beltrán Catalán S, Escudero Quesada V, et al. (2009) Use of basiliximab induction in lowimmunological risk renal transplant recipients receiving tacrolimus-based immunosuppression. Transplant Proc 41: 2337-2338.

51. Hellemans R, Bosmans JL, Abramowicz D (2017) Induction Therapy for Kidney Transplant Recipients: Do We Still Need Anti-IL2 Receptor Monoclonal Antibodies? Am J Transplant 17: 22-27.

52. Tanriover B, Zhang S, MacConmara M, Gao A, Sandikci B, et al. (2015) Induction therapies in live donor kidney transplantation on tacrolimus and mycophenolate with or without steroid maintenance. Clin J Am Soc Nephrol 10: 1041-1049.

53. Willoughby LM, Schnitzler MA, Brennan DC, Pinsky BW, Dzebisashvili N et al. (2009) Early outcomes of thymoglobulin and basiliximab induction in kidney transplantation: application of statistical approaches to reduce bias in observational comparisons. Transplantation 87: 1520-1529.
54. Gralla J, Wiseman AC (2010) The impact of IL2ra induction therapy in kidney transplantation using tacrolimus- and mycophenolate-based immunosuppression. Transplantation 90: 639-644.

55. Lim WH, Chadban SJ, Campbell S, Dent H, Russ GR, et al. (2010) Interleukin-2 receptor antibody does not reduce rejection risk in low immunological risk or tacrolimus-treated intermediate immunological risk renal transplant recipients. Nephrology (Carlton) 15: 368-376.

56. Tanriover B, Jaikaransingh V, MacConmara MP, Parekh JR, Levea SL, et al. (2016) Acute rejection rates and graft outcomes according to induction regimen among recipients of kidneys from deceased donors treated with tacrolimus and mycophenolate. Clin J Am Soc Nephrol 11: 1650-1661.

57. Mourad G, Rostaing L, Legendre C, Garrigue V, Thervet E, et al. (2004) Sequential protocols using basiliximab versus anti-thymocyte globulins in renal-transplant patients receiving mycophenolate mofetil and steroids. Transplantation 78: 584-590.

58. Al Najjar A, Etienne I, Le Pogamp P, Bridoux F, Le Meur Y, et al. (2006) Long-term results of monoclonal anti-IL2-receptor antibody versus polyclonal antilymphocyte antibodies as induction therapy in renal transplantation. Transplant Proc 38: 2298-2299.

59. Chapal M, Foucher Y, Marguerite M, Neau K, Papuchon E, et al. (2015) PREventing Delayed Graft Function by Driving Immunosuppressive InduCtion Treatment (PREDICT-DGF): study protocol for a randomized controlled trial. Trials 16: 282 . 